\title{
GASTO ENERGÉTICO NO RECÉM-NASCIDO E LACTENTE COM SEPSE
}

\section{ENERGETIC SPENT IN THE NEWBORN AND INFANT WITH SEPSIS}

\author{
Rubens Feferbaun ${ }^{1}$ \\ Adriana Gonçalves de Oliveira ${ }^{2}$ \\ Vitor Engrácia Valenti ${ }^{3}$ \\ Luiz Carlos de Abreu ${ }^{4}$
}

Feferbaun R, Oliveira AG, Valenti VE, Abreu LC. Gasto energético no recém-nascido e lactente com sepse. Rev Bras Crescimento Desenvolv Hum. 2009; 19(1): 122-133.

\section{Resumo:}

Introdução: as necessidades nutricionais e particularmente o metabolismo energético de crianças são temas controversos na literatura. Objetivo: caracterizar o gasto energético em repouso em recém-nascidos e lactentes com sepse. Método: foram consultadas as bases de dados do Medline, SciELO, BVS Pepsic e Lilacs. Utilizou-se como estratégia de busca no MEDLINE newborn and energy spent or sepsis em todos os campos. Resultados: recémnascidos e lactentes em casos de sepse grave apresentam imaturidade dos sistemas enzimáticos, limitando a produção de alguns aminoácidos como a cisteína (deficiência da enzima cistationase em pré-termo), taurina, glutamina e nucleotídeos como colina e inositol. Este fato torna estes nutrientes condicionalmente essenciais para estas população. Conclusão: vários conceitos estabelecidos para adultos são transpostos para a faixa pediátrica, o que é inadequado, podendo ocasionar graves conseqüências à saúde dos recém-nascidos e lactentes.

Palavras-chave: sepse; recém-nascido; metabolismo; infecção.

1 Livre-docente. Departamento de Pediatria, Faculdade de Medicina, Universidade de São Paulo, SP.

2 Médica Neonatologista. Médica-chefe do setor de Cuidados Intermediários do Hospital Maternidade Leonor Mendes de Barros, São Paulo, SP.

3 Pesquisador em nível de doutorado, Departamento de Medicina, Disciplina de Cardiologia, Universidade Federal de São Paulo, São Paulo, SP.

4 Pós-doutor em Saúde Pública. Professor do Departamento de Fisiologia. Faculdade de Medicina do ABC. Correspondência para: Rubens Feferbaum. Departamento de Pediatria, Faculdade de Medicina, Universidade de São Paulo, Av. Dr. Enéas de Carvalho de Aguiar n ${ }^{\circ}$ 647. Cerqueira César. 05403900 - Sao Paulo, SP - Brasil. Tel: (11) 3069-8590 


\begin{abstract}
:
Introduction: the nutritional needs and particularly, the energetic metabolism in childhood is a controversy in the literature. Objective: to characterize the energetic spent at rest in infants with sepsis. Method: the database of Medline, SciELO and Lilacs was consulted. We used as search strategy the words: newborn and energy spent or sepsis in all fields. Results: In the case of sepsis, the child presents immaturity of the enzymatic system, which limits the production of some aminoacids, such as cystein (cistationase enzyme deficit in preterm), taurine, gutamine and nucleotides as coline e inositol. This fact turns those nutrients conditionally essential for children. Conclusion: many concepts for adults are used in childohood, which is not correct and may cause several consequences to the health of infants.
\end{abstract}

Key words: sepsis; newborn; metabolism; infection, infants.

\section{INTRODUÇÃO}

A nutrição adequada é essencial na manutenção da homeostase do ser humano. As necessidades nutricionais da criança, em particular do lactente e do recém-nascido (RN), são muito diferentes das verificadas em adultos, especialmente devido às suas necessidades de crescimento e desenvolvimento. ${ }^{1}$

Durante o primeiro ano de vida, o RN de termo adequado para a idade gestacional dobra seu peso de nascimento aos cinco meses de vida e triplica no final do primeiro ano de vida; o comprimento da criança normal aumenta, em média, 25-30 cm no primeiro ano de vida, o que representa um incremento de 75 a 85\% em relação ao nascimento. A maioria dos órgãos cresce nesta fase da vida: o cérebro aumenta dois terços do tamanho que terá no final da vida adulta. Em conseqüência do rápido crescimento, as necessidades dos nutrientes e energia são altas para o RN (especialmente pré-termo) e lactente, sendo as maiores de toda a vida do ser humano. ${ }^{2}$ No entanto, este quadro pode ser modificado pela doença que acomete o RN e lactente. As infecções no período neonatal, das mais freqüentes em nosso meio, certamente contribuem como causa importante nas taxas de morbimortalidade neonatal. ${ }^{3}$

Os efeitos dos macro e micronutrientes no sistema imunológico em desenvolvimento são bem documentados e a presença da desnutrição durante o período pós natal imediato, melhor definida pela aplicação do escore Z, afeta de maneira importante as defesas do organismo. ${ }^{4}$

Na presença de infecção grave, a resposta metabólica é caracteristicamente aumentada; nesta situação, o metabolismo energético em adultos é alto em função das necessidades da doença. Há modificações importantes no metabolismo protéico; ocorre proteólise acentuada das proteínas muscular e visceral sendo os aminoácidos assim originados consumidos na geração de glicose e ressíntese protéica de fatores imunológicos, tais como anticorpos e proteínas de fase aguda, dentre as quais destaca-se a proteína C reativa. ${ }^{5}$ Entretanto, apesar dos numerosos estudos que avaliam as necessidades nutricionais do RN de termo ou prétermo saudáveis, pouco se sabe a respeito da 
resposta metabólica e das necessidades do RN gravemente infectado. ${ }^{6}$

O estudo do metabolismo energético no RN e no lactente com sepse é tema controverso devido às modificações ocasionadas pelo seu crescimento, composição dos nutrientes da alimentação e, sobretudo, da interação nutriçãodoença que afeta profundamente estas crianças. Com base na análise da literatura, nossa impressão é de que o suporte nutricional do $\mathrm{RN}$ e do lactente gravemente doentes com sepse não está resolvido; suas necessidades metabólicas estão aumentadas pela doença e a falta ou o excesso de oferta de nutrientes pode ocasionar efeitos deletérios ao RN. As necessidades nutricionais e particularmente o metabolismo energético destas crianças é tema controverso na literatura e motivo desta pesquisa. Assim, o objetivo é caracterizar o gasto energético em repouso (GER) em recém-nascidos e lactentes com sepse.

\section{MÉTODO}

Foram consultadas as bases de dados: MEDLINE/PUBMED (Literatura Internacional em Ciências da Saúde) e SciELO (Scienfic Eletronic Library).

As seguintes estratégias de busca foram utilizadas: MEDLINE/PUBMED: utilizaramse os termos de busca newborn AND energy spent OR sepsis para encontrar os trabalhos de que contivessem o termo em qualquer campo. Foram usados como limites de busca: subset Medline e referências nos idiomas inglês e português.

SciELO, BVS PePSIC e LILACS: em busca avançada, pesquisou-se ano a ano (2001 a 2008), utilizando o termo nutrition in newborn AND energy spenty AND sepsis em todos os campos. A seleção dos artigos foi realizada manualmente e excluídos os que mencionavam newborn sem a ligação com energy spent. Os artigos duplicados foram excluídos nas bases de dados, prevalecendo aquela de maior abrangência e na seguinte ordem: MEDLINE/PUBMED, SciELO, BVS PePSIC e LILACS.

O conceito de prematuridade inclui todo recém-nascido ( $\mathrm{RN})$ vivo com menos de 37 semanas completas de gestação ( $<259$ dias) contadas a partir do primeiro dia do último período menstrual. Os recém-nascidos pré-termo com peso inferior a 1500 g são denominados pré-termo de muito baixo peso. ${ }^{7,8}$

\section{RESULTADOS E DISCUSSÃO}

\section{Metabolismo em recém-nascidos}

As necessidades energéticas para os processos metabólicos no organismo são supridas pela degradação de produtos contendo fosfato, especialmente o trifosfato de adenosina (ATP). Estes compostos não estão disponíveis em estoques e por este motivo, têm necessidade de síntese contínua. ${ }^{9}$ Os hidratos de carbono, as gorduras e os aminoácidos são os substratos preferenciais para a formação do ATP (Figura 1) e possuem diferentes balanços de energia (Quadro 1).

A oxidação dos hidratos de carbono implica na entrada de glicose para a via de Embden-Meyerhof; o ATP pode ser gerado por metabolismo anaeróbico do piruvato derivado da glicose ou da conversão de piruvato para 
Figura 1: Vias do metabolismo energético.

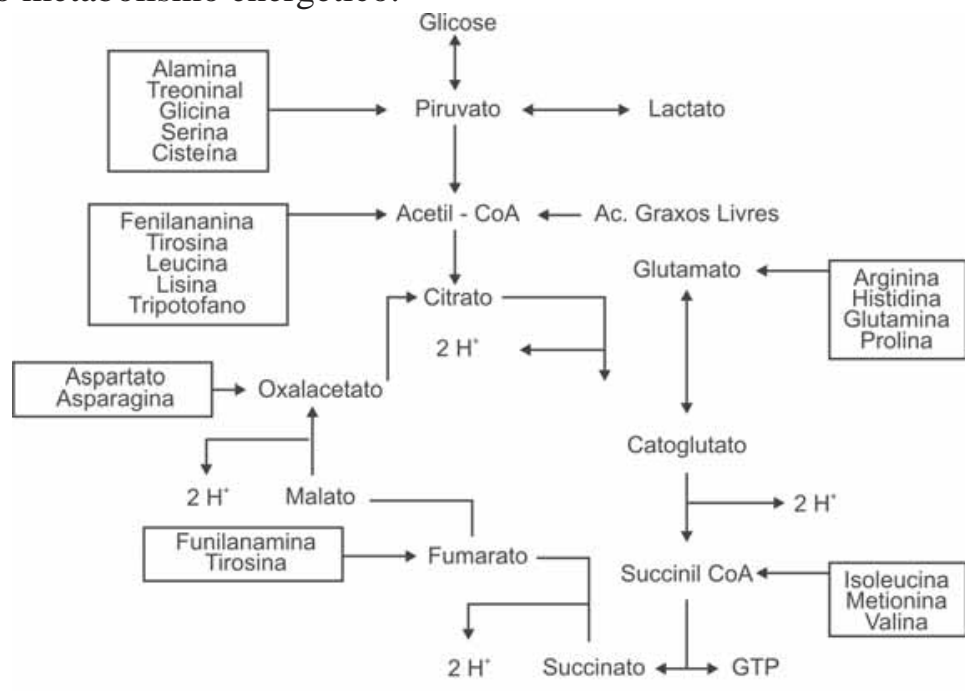

DEUTSCHMAN, 1992 modificado por DELGADO, 1994

Quadro 1: Balanço de energia dos três principais nutrientes.*

\begin{tabular}{|c|c|c|c|}
\hline & $\begin{array}{c}\text { Glicose } \\
(180)\end{array}$ & $\begin{array}{c}\text { Palmitato } \\
(256,4) \dagger\end{array}$ & $\begin{array}{c}\text { Proteina } \\
(88) \dagger\end{array}$ \\
\hline $\begin{array}{l}\text { (a) Calor liberado (kcal) } \\
\text { por mol oxidado } \\
\text { por grama oxidado }\end{array}$ & $\begin{array}{c}673 \\
2.398\end{array}$ & $\begin{array}{c}2,398 \\
93\end{array}$ & $\begin{array}{l}475 \\
5,4\end{array}$ \\
\hline $\begin{array}{l}\text { (b) } \mathrm{O}_{2} \text { consumido } \\
\text { (mol) } \\
\text { (litros) }\end{array}$ & $\begin{array}{c}66 \\
134\end{array}$ & $\begin{array}{c}23 \\
515\end{array}$ & $\begin{array}{l}5,1 \\
114\end{array}$ \\
\hline $\begin{array}{l}\text { (c) } \mathrm{CO}_{2} \text { produzido } \\
\text { (mol) } \\
\text { (litros) }\end{array}$ & $\begin{array}{c}66 \\
134\end{array}$ & $\begin{array}{c}16 \\
358\end{array}$ & $\begin{array}{c}4,1 \\
92\end{array}$ \\
\hline $\begin{array}{l}\text { (d) Número de ATP } \ddagger \text { produzido§ } \\
\text { (mol) }\end{array}$ & 36 & 129 & 23 \\
\hline $\begin{array}{l}\text { Custo do ATP: } \\
\text { Energia kcal/mol de ATP (a/d) } \\
\mathrm{O}_{2} \mathrm{~L} / \mathrm{mol}(\mathrm{b} / \mathrm{d}) \\
\mathrm{CO}_{2} \mathrm{~L} / \mathrm{mol}(\mathrm{c} / \mathrm{d})\end{array}$ & $\begin{array}{l}18,7 \\
3,72 \\
3,72\end{array}$ & $\begin{array}{l}18,3 \\
3,99 \\
2,77\end{array}$ & $\begin{array}{l}20,7 \\
4,96 \\
4,00\end{array}$ \\
\hline Quociente respiratório (c/b) & 1 & 0,7 & 0,81 \\
\hline $\begin{array}{l}\text { Energia equivalente (ou produzi- } \\
\text { da por) de um litro de oxigênio } \\
\text { oxidado (Kcal/L) }\end{array}$ & 5,02 & 4,66 & 4,17 \\
\hline
\end{tabular}

* Modificado por FERRANNINI, 1978.

$\dagger$ Peso molecular

¥ ATP = adenosina-5-trifosfato

§ Disponível biologicamente 
acetil-coenzima (AcetilCoA) com a conseqüente entrada no ciclo dos ácidos tricarboxílicos. ${ }^{10}$ De maneira semelhante, a beta oxidação dos ácidos graxos para acetilCoA promove a entrada destes substratos no ciclo de Krebs, podendo as gorduras também ser convertidas em corpos cetônicos, metabolizados para acetilCoA e desta maneira ingressar no ciclo dos ácidos tricarboxílicos. ${ }^{10}$

Diversos aminoácidos podem servir como precursores da acetilCoA em condições fisiológicas especiais; outros entram no ciclo dos ácidos tricarboxílicos como alfa-cetoglutarato, succinilCoA, fumarato, ou oxalacetato. Parte dos aminoácidos serve como substrato para a neoglicogênese no fígado e rins. ${ }^{10}$

O glicogênio, fonte vital de energia para o recém-nascido (RN) nas primeiras horas de vida, acumula-se especialmente no fígado ( $5 \%$ do seu peso) e no músculo cardíaco (4\% do peso). Estes estoques são prejudicados quando ocorre prematuridade, retardo de crescimento intra-útero ou anoxia neonatal. ${ }^{11}$

Diversos hormônios estão envolvidos no metabolismo energético do RN; a insulina aparece no pâncreas fetal a partir da $12^{\mathrm{a}}$ semana de gestação, mas não apresenta importância no armazenamento de substratos energéticos. Ao nascimento, o resfriamento corpóreo, o trabalho da respiração, a atividade e a anoxia ocasionam aumento da demanda energética. O RN consome sua reserva de glicogênio em duas ou três horas de vida e precisa alterar seu metabolismo para a manutenção dos níveis glicêmicos adequados; assim, a primeira resposta é a glicogenólise. Posteriormente, ocorre lipólise e aumento plasmático dos ácidos graxos. O quociente respiratório (QR) cai durante os três primeiros dias de vida, denotando consumo de gorduras, mediado principalmente pelas catecolaminas e hormônio de crescimento. ${ }^{11}$

O nível de glicemia no RN de Termo é de 60 a 70\% do nível simultâneo materno. A glicemia cai nas primeiras duas horas de vida para o mínimo aceitável de $35-40 \mathrm{mg} / \mathrm{dl}$ e sobe pela sexta hora de vida para $45-60 \mathrm{mg} / \mathrm{dl} .{ }^{12}$

A avaliação do gasto energético tem utilizado a técnica de radioisótopos denominada “água duplamente marcada”. A técnica consiste na determinação de água marcada com $\mathrm{H}_{2}$ (deutério) e $\mathrm{O}_{18}$ administrada ao indivíduo; a geração de água é proporcional ao gasto energético. A perda do isótopo do organismo é monitorada durante dias, havendo uma relação direta entre o desaparecimento do $\mathrm{H}_{2}$ e $\mathrm{O}_{18}$ e a produção de $\mathrm{CO}_{2}$. Desta maneira, conhecendo-se o QR, calcula-se o gasto energético. A vantagem desta técnica é a de que o gasto energético pode ser estimado de forma não invasiva durante o período de dias. O método exige volume de água corpóreo constante não sendo adequado para RN doentes. ${ }^{13}$

A taxa metabólica em repouso (TMR) ou gasto energético em repouso (GER) corresponde ao gasto energético nas mesmas condições da TMB, exceto quanto ao fato de ser medido após a refeição ou atividade normal. Esta é a condição mais verificada no RN e lactente e mais freqüentemente determinada. ${ }^{14}$

A TMB muda com a composição corpórea. Passmore et $\mathrm{al}^{15}$ verificaram que a taxa varia em função da massa magra do indivíduo. A idade é outro fator que altera a TMB: esta é maior nos primeiros anos de vida, 
diminui na infância e aumenta na adolescência. Após a puberdade, a TMB diminui com a idade.

Outras variáveis influenciam a TMB; sexo: a TMB no sexo feminino é 5 a 10\% menor que o do masculino, fato este atribuído ao maior acúmulo de gordura nas mulheres. ${ }^{16}$ Quanto ao estado nutricional, a TMB pode estar normal ou pouco diminuída em crianças desnutridas (tanto no tipo marasmo ou no
Kwashiorkor) e aumenta na fase de recuperação nutricional, variando de 118 a 206\% dos níveis normais. ${ }^{17}$

A energia estocada é a energia utilizada principalmente para o crescimento, acumulando proteínas e gordura. Verifica-se em lactentes que a energia utilizada para o crescimento é a mais importante após o metabolismo basal e corresponde a aproximadamente 20 a $35 \%$ da TMB (Figura 2). ${ }^{17}$

Figura 2: Componentes do balanço de energia no recém-nascido.

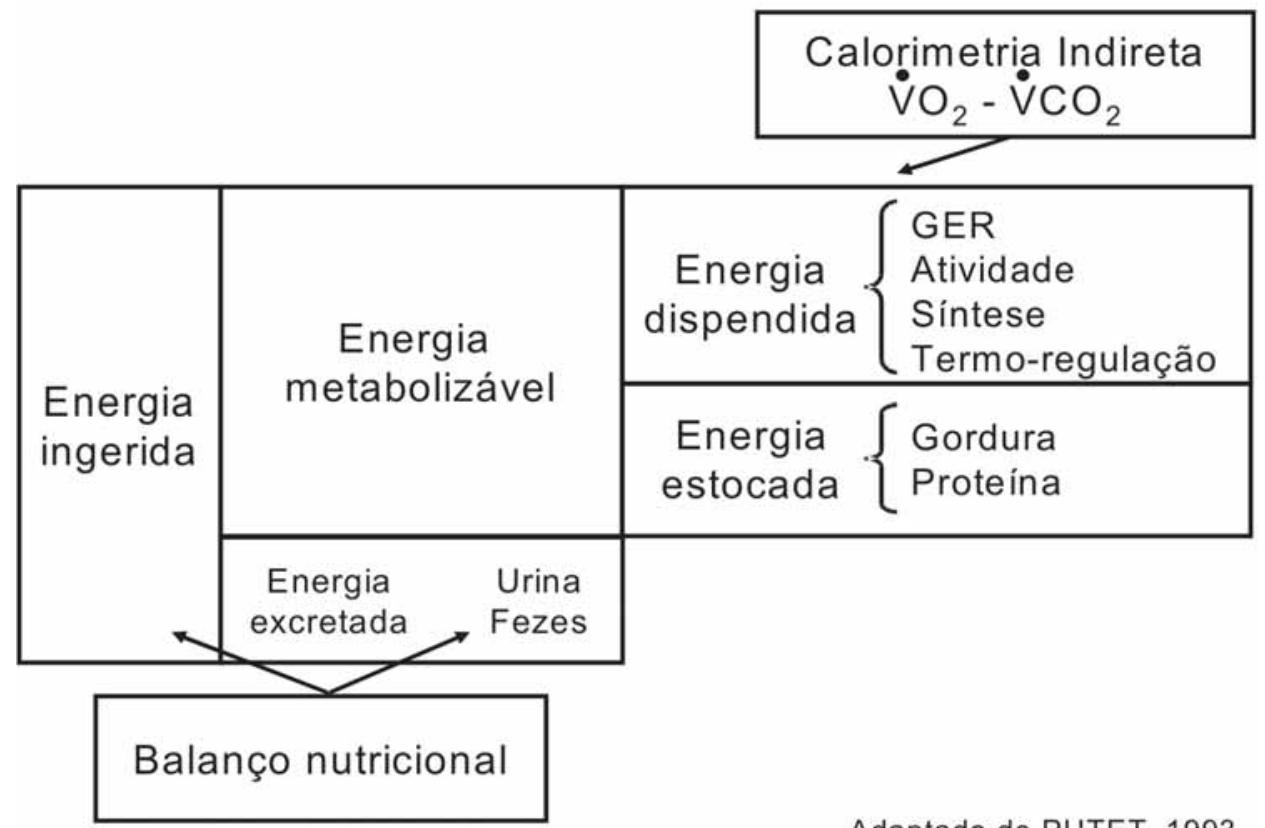

Adaptado de PUTET, 1993

As funções orgânicas ${ }^{18}$ refletem o estado hipermetabólico com as seguintes manifestações clínicas: a) Cardiovascular: aumento do débito cardíaco, vasodilatação periférica, expansão do compartimento vascular; b) Pulmonar: aumento da freqüência respiratória e da ventilação minuto, desbalanço da relação ventilação/perfusão; c) Renal: perda da capacidade de concentração e diluição, retenção de água e sal; d) Hepática: neoglicogênese, prejuízo na síntese protéica e na excreção biliar; e) Gastrointestinal: íleo adinâmico, depleção enzimática da borda em escova da mucosa intestinal com má absorção de nutrientes e perda da integridade da barreira da mucosa, facilitando a translocação bacteriana; f) Musculatura esquelética: proteólise; g) Tecido adiposo: lipólise. 
A criança que apresenta estresse metabólico não apresenta de forma tão definida as fases citadas. Alguns estudos e revisões, especialmente na criança e particularmente no RN com sepse bacteriana, demonstram que a presença das citocinas tais como a interleucina-1, interleucina-6 e fator de necrose tumoral, associadas aos hormônios tireoideano e de crescimento, levam a um aumento no consumo de oxigênio. ${ }^{19}$ Em condições normais o RN tem alto consumo de $\mathrm{O}_{2}$, direcionado principalmente para o cérebro, coração, rins e fígado, que corresponde a $60-70 \%$ do total de $\mathrm{O}_{2}$ disponível no sangue circulante. O tênue equilíbrio da oxigenação celular depende de um balanço dinâmico entre o fluxo sangüíneo, a extração tecidual e o conteúdo sangüíneo de $\mathrm{O}_{2}$, facil- mente alterado na condição de sepse neonatal. A resultante má distribuição do fluxo sangüíneo, o aumento do consumo de $\mathrm{O}_{2}$, e as alterações metabólicas como a acidose, propiciam o estado hipermetabólico e a disfunção múltipla de órgãos e sistemas. ${ }^{19}$

As infecções agudas podem ocasionar uma resposta metabólica generalizada que conduz ao hipermetabolismo e ao catabolismo com a resultante perda de proteína celular somática e depleção dos estoques de nutrientes orgâni$\cos ^{20}$

Foi observado que a TMB associada ao trauma grave pode variar até $40 \%$ a mais na condição referida (Figura 3).

O processo metabólico verificado durante o jejum difere daquele verificado na sepse ou no

Figura 3: Modificações do metabolismo basal no decorrer do tempo em função do nível de estresse.

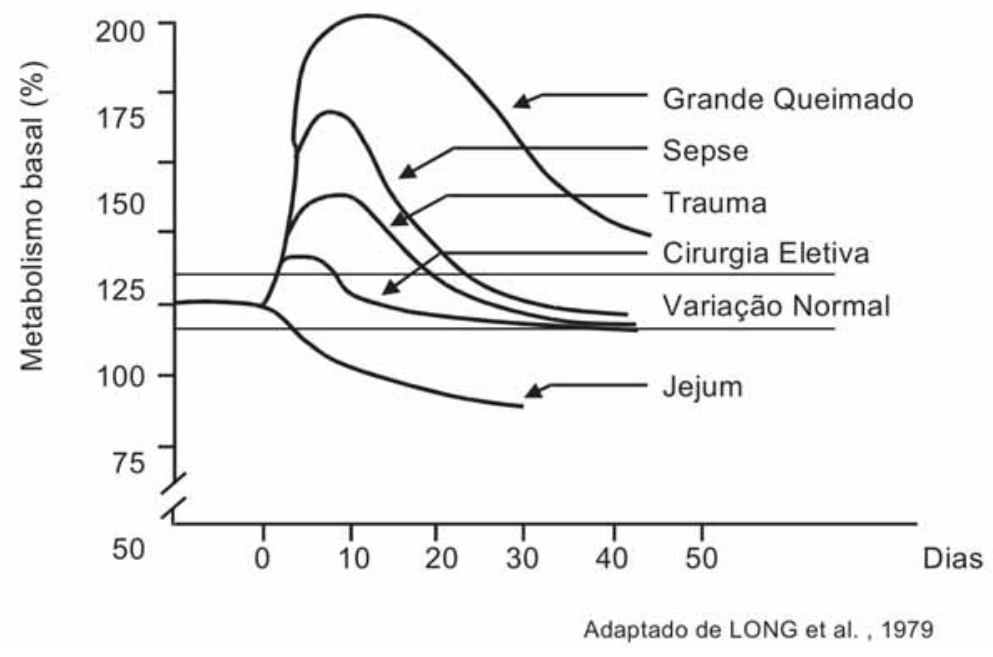

Aumentos mais acentuados de mais de 50\% da TMB foram descritos em infecções com resposta inflamatória intensa, como na peritonite e no empiema pleural. No grande queimado a TMB pode aumentar até 100\%.
Baseadas nestes valores, foram elaboradas tabelas que corrigem as necessidades calóricas no paciente hipermetabólico através do fator de estresse variável segundo a condição clínica do paciente (Quadro 2). ${ }^{21}$ 
Quadro 2: Fatores de estresse (correção das necessidades calóricas no hipermetabolismo ocasionado pela doença).

\begin{tabular}{lc}
\hline Pós - operatório ( sem complicações) & 1,0 \\
Fratura de osso longo & $1,15-1,30$ \\
Câncer & $1,10-1,30$ \\
Peritonite/ Sepse & $1,10-1,30$ \\
Infecção grave/ Trauma múltiplo & $1,20-1,40$ \\
Síndrome de falência de múltiplos órgãos & $1,20-1,40$ \\
Queimadura & \\
(= GER aproximado + \% de área corpórea queimada) & $1,20-2,0$ \\
\hline
\end{tabular}

Necessidades Energéticas Corrigidas (Kcal/dia) = GER x fator de estresse

( Adaptado de ESCALLÓN, 1997)

trauma: não ocorre hipermetabolismo. Ao contrário, a TMB pode estar diminuída, a autofagia protéica é menos acentuada e há mobilização de gorduras. A hidrólise de uma molécula de triglicerídeo produz três ácidos graxos; estes são transportados pela albumina e utilizados no coração, músculos esqueléticos, fígado e rins. O glicerol, um componente do triglicerídeo, é re- movido pelo fígado para a síntese de glicose no jejum. Os triglicerídeos são excelentes fontes para armazenar energia $(9,4 \mathrm{Kcal} / \mathrm{g}) .{ }^{10}$

As diferenças entre o metabolismo no jejum e na sepse ou trauma estão esquematizadas no Quadro 3.

As infecções agudas aceleram a síntese e o catabolismo das proteínas corpóreas. Al-

Quadro 3: Resposta metabólica no jejum e estresse.

\begin{tabular}{lcc} 
& Jejum & Estresse \\
Taxa metabólica & $\downarrow$ & $\uparrow \uparrow$ \\
Reserva energética & Conservada & Consumida \\
Proteína corpórea & Conservada & Consumida \\
Nitrogênio urinário & $\downarrow$ & $\uparrow \uparrow$ \\
Perda de peso & Lenta & Rápida \\
\hline
\end{tabular}

Modificado de Escallón, 1997. Alterações metabólicas durante a sepse.

guns mediadores endógenos que incluem citocinas e hormônios catabólicos como os corticosteróides, estimulam o catabolismo de proteínas do músculo esquelético. Durante a infecção e trauma grave a proteína muscular sofre proteólise, sendo rapidamente mobilizada para atender às necessidades de defesa or- gânica na síntese de proteínas de fase aguda como a proteína C reativa (PCR), anticorpos e imunoglobulinas, entre outros. ${ }^{22}$

Durante a sepse grave aumentam as concentrações plasmáticas de aminoácidos contendo enxofre como taurina, cisteína e metionina. Os aminoácidos são importantes 
substratos para a neoglicogênese hepática; o componente nitrogenado da alanina permite maior síntese de uréia, sendo este o principal processo de geração de uréia na infecção grave. ${ }^{4}$

O balanço nitrogenado na sepse é negativo. Os processos catabólicos e a utilização dos aminoácidos para produção de energia contribuem para este fato. Parte do balanço negativo é devida à anorexia; no entanto, a perda nitrogenada diária de um adulto com sepse situa-se em 20g/dia. É interessante notar que este balanço negativo é pouco revertido pelo uso de nitrogênio exógeno. ${ }^{4}$

Por meio de estudos de balanço nitrogenado em diversas condições clínicas foram relatadas perdas nitrogenadas de até $35 \mathrm{~g} /$ dia, o que corresponde à perda de $1 \mathrm{~kg}$ de massa magra por dia. ${ }^{23} \mathrm{~A}$ figura 4 mostra que a perda urinária de nitrogênio aumenta com a gravidade da doença ou trauma sendo proporcional ao aumento da TMB.

O RN séptico também se apresenta hipermetabólico, com catabolismo protéico que

Figura 4: Efeitos do estresse na perda de nitrogênio e taxa metabólica basal.

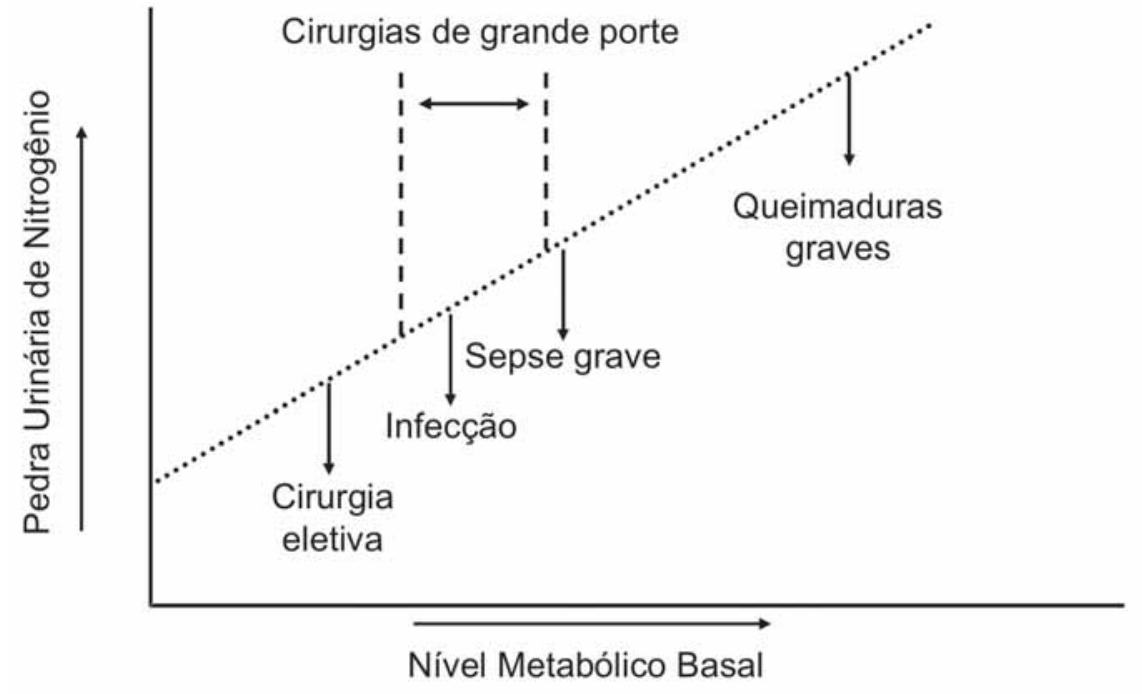

Adaptado de LONG et al., 1979

depleta os estoques de glutamina e alanina (45\% do total de aminoácidos). A conseqüência deste fato é a grave atrofia da mucosa intestinal, com perda da função imunitária e facilitação da translocação bacteriana. ${ }^{24}$

O desbalanço dos aminoácidos intracelulares nos pacientes com hipercatabolismo pode ser um dos problemas fundamentais da nutrição celular, afetando de forma adversa a síntese protéica. Nas soluções parenterais atualmente utilizadas para o recémnascido, as ofertas de glicina, fenilalanina, leucina e treonina são grandes, enquanto que as necessidades de valina, serina, lisina e histidina são relativamente pequenas para o paciente gravemente doente. Os aminoácidos como glutamina, tirosina, cisteína e taurina não estão incluídos normalmente na nutrição 
parenteral por se apresentarem de forma insolúvel ou pouco metabolizável. Para melhor adequação nutricional estes aminoácidos devem ser incorporados nas formulações de nutrição parenteral do RN. ${ }^{25}$

A glutamina, especificamente, parece ser um aminoácido importante na manutenção do trofismo da mucosa intestinal e manutenção da barreira mucosa. ${ }^{25}$

Os RN gravemente doentes e especialmente os pré-termo, apresentam imaturidade dos sistemas enzimáticos, limitando a produção de alguns aminoácidos como a cisteína (deficiência da enzima cistationase em pré-termo), taurina, glutamina e nucleotídeos como colina e inositol. Este fato torna estes nutrientes condicionalmente essenciais para esta po- pulação. ${ }^{26} \mathrm{O}$ quadro 4 mostra a consequência da hiper alimentação em RN gravemente doentes.

Destaca-se que a nutrição deve receber cuidado especial para garantir o crescimento e o desenvolvimento neuropsicomotor adequados e evitar seqüelas futuras. A avaliação nutricional realizada através das medidas antropométricas e, mais recentemente, através do índice de massa corpórea deve ser contínua. A introdução de nutrição parenteral e/ou enteral precoce deve ser considerada uma rotina, com a finalidade de garantir um ganho de peso adequado e uma recuperação mais rápida durante a hospitalização dos RN. ${ }^{27}$

Desta maneira, apesar da complexidade e das dificuldades da nutrição nos

Quadro 4: Conseqüências da hiper alimentação no recém-nascido (RN) gravemente doente.

Hipertrigliceridemia

Hiperglicemia

Hiperosmolaridade

Diurese osmótica

Desidratação

Complicações respiratórias

Aumento da produção de $\mathrm{CO}_{2}$

Aumento do volume minuto

Disfunção hepática

Prolonga o suporte ventilatório

Depósito de gordura

Colestase

Esteatose

Hepatomegalia

Azotemia

Piora da função imune

lactentes e recém-nascidos gravemente enfermos, diversos conceitos estabelecidos para adultos são transpostos para a faixa neonatal e pediátrica, o que é inadequado, podendo ocasionar graves conseqüências à saúde desta população. 


\section{REFERÊNCIAS}

1. Barness LA. Recent articles of nutritional interest tb pediatricians. Curr Probi Pediatr. 1991; 21(7):293-6.

2. Litt R, Seidman DS, Gross-Tsur V, Dollberg S, Gale R. A 2-year prospective study of very low birthweight infants. Isr J Med Sci. 1992;28(11):783-8.

3. Ceccon ME, Diniz EM, CarneiroSampaio MM, Arslanian C, Diogo CL, Ramos JL, Vaz FA. Immurological behavior (IgG, $\lg \mathrm{M}, \lg \mathrm{A})$ and total complement (CH50) of newborns infants with risk factors for early onset sepsis. Comparative analysis of newborns with and without infection.

Rev Hosp Clin Fac Med Sao Paulo.1998;53(6):303-10.

4. Beisel MJ. Alaska nurse practitioners' and physician assistants' perceptions of the collaboration process. J Am Acad Nurse Pract.1998;10(11):509-14.

5. Deutschmann A, Mache CJ, Bodo K, Zebedin D, Ring E. Successful treatment of chronic recurrent multifocal osteomyelitis with tumor necrosis factoralpha blockage. Pediatrics. 2005; 116(5):1231-3.

6. Cañete A, Duggan C. Nutritional support of the pediatric intensive care unit patient. Curr Opin Pediatr.1996; 8(3):248-55.

7. Abreu, LC, Souza, AMB, Oliveira, AG et al. incidência de hemorragia periintraventricular em recém-nascidos prétermo e a relação com o peso ao nascer. Rev. bras. crescimento desenvolv. hum., 2007; 17(2):24-30.
8. Anderson D. Nutritional assessment and therapeutic interventions for the preterm infant. Clin Perinatol., 2002; 29:313-26.

9. Cerra FB. Hypermetabolism-organ failure syndrome: a metabolic response to injury. Crit Care Clin. 1989; 5(2):289-302.

10. Bagley JS, Wan JM, Georgieff M, Forse RA, Blackburn GL. Cellular nutrition in support of early multiple organ failure. Chest. 1991; 100(3 Suppl): 182S-188S.

11. Wald N, Barker S, Cuckle H, Brock D, Stirrat G. Fetal loss after amniocentesis. Lancet.1978; 2(8099): 1093

12. Schwartz FT, Paltauf F. Studies on the interaction of cholesterol with diesterand dietherlecithin. Chem Phys Lipids. 1976; 17(4):423-34.

13. Jones CD, Jarjou MS, Whitehead RG, Jequier E. Fatness and the energy cost of carrying loads in African women. Lancet. 1987; 2(8571):1331-2.

14. Garcia Roig F, Hicks Gomez JJ. Prenatal diagnosis by ultrasonography. A rndomized study of 3000 patients. Ginecol Obstet Ihex. 1991; 59:323-7.

15. Passmore R. Nutrition balance techniques and their limitations. Energy balances in man. Proc Nutr Soc. 1967; 26(1):97-101.Warburg effect: the metabolic requirements of cell proliferation. Science. 2009;324(5930):1029-33.

16. Behnke AR. The relation of lean body weight to metabolism and some consequent systematizations. Ann N Y Acad Sci. 1953; 56(6):1095-1142.

17. Montgomery RD. Muscle morphology in infantile protein malnutrition. J Clin Pathol. 1962; 15(6):511-21. 
18. Vander Heiden MG, Cantley LC, Thompson CB. Understanding the Warburg effect: the metabolic requirements of cell proliferation. Science. 2009; 324(5930):1029-33.

19. Owens JL, Musa N. Nutrition support after neonatal cardiac surgery. Nutr Clin Pract. 2009; 24(2):242-9.

20. Hopkin J. Immune and genetic aspects of asthma, allergy and parasitic worm infections: evolutionary links. Parasite Immunol. 2009; 31(5):267-73.

21. Shulman ST. Pediatric autoimmune neuropsychiatric disorders associated with streptococci PANDAS): update. Curr Opin Pediatr. 2009; 21(1):127-30.

22. Buret AG. Pathophysiology of enteric infections with Giardia duodenalius. Parasite. 2008; 15(3):261-5.

23. Nair L, Nair MK, Chacko DS. Markers of fetal onset adult diseases. Indian Pediatr. 2009; 46 Suppl:s48-54.

24. Dowley AC, Whitehouse WP, Mason
SM, Cope Y, Grant J, Gibbin KP.

Auditory neuropathy: unexpectedly common in a screened newborn population. Dev Med Child Neurol. 2009 Mar 20. [Epub ahead of print]

25. Guerrant RL, Oriá RB, Moore SR, Oriá MO, Lima AA. Malnutrition as an enteric infectious disease with long-term effects on chiid development. Nutr Rev. 2008; 66(9):487-505.

26. Jahoor F, Badaloo A, Reid M, Forrester T. Protein metabolism in severe childhood malnutrition. Ann Trop Paediatr. 2008; 28(2):87-101.

27. Oliveira AG, Siqueira PP, Abreu LC. Cuidados nutricionais no recém-nascido de muito baixo peso. Rev. bras crescimento desenvolv hum., ago. 2008, vol.18, nº 2, p.148-154.

28. Feferbaum R; Quintal VS. Nutrição enteral do recém-nascido pré-termo. Rev. Pediatria Moderna, São Paulo, v. 36, p. 133-140, 2000.

Recebido em: 23/10/2008 Modificado em: 07/11/2008 Aceito em: 04/02/2009 